NBER WORKING PAPER SERIES

\title{
THE DEMAND FOR CIGARETTES AS DERIVED FROM THE DEMAND FOR WEIGHT CONTROL
}

\author{
John Cawley \\ Stephanie von Hinke Kessler Scholder \\ Working Paper 18805 \\ http://www.nber.org/papers/w18805
}

\author{
NATIONAL BUREAU OF ECONOMIC RESEARCH \\ 1050 Massachusetts Avenue \\ Cambridge, MA 02138 \\ February 2013
}

We thank David Frisvold, Don Kenkel, and Catherine Maclean, as well as participants in the American Society of Health Economists biennial conference and the Food \& Drug Administration's Economics of Tobacco Roundtable, for their helpful comments. We gratefully acknowledge financial support from: Cornell's Institute for Health Economics, Health Behaviors, and Disparities (Cawley) and the UK Medical Research Council (von Hinke Kessler Scholder; MRC Early Career fellowship in the economics of health, reference number G1002345). The views expressed herein are those of the authors and do not necessarily reflect the views of the National Bureau of Economic Research.

NBER working papers are circulated for discussion and comment purposes. They have not been peerreviewed or been subject to the review by the NBER Board of Directors that accompanies official NBER publications.

(C) 2013 by John Cawley and Stephanie von Hinke Kessler Scholder. All rights reserved. Short sections of text, not to exceed two paragraphs, may be quoted without explicit permission provided that full credit, including $(\mathrm{C}$ notice, is given to the source. 
The Demand for Cigarettes as Derived from the Demand for Weight Control

John Cawley and Stephanie von Hinke Kessler Scholder

NBER Working Paper No. 18805

February 2013

JEL No. D01,H2,H3,I1,Z18

\begin{abstract}
$\underline{\text { ABSTRACT }}$
We provide new evidence on the extent to which the demand for cigarettes is derived from the demand for weight control (i.e. weight loss or avoidance of weight gain). We utilize nationally representative data that provide the most direct evidence to date on this question: individuals are directly asked whether they smoke to control their weight. We find that, among teenagers who smoke frequently, $46 \%$ of girls and $30 \%$ of boys are smoking in part to control their weight. This practice is significantly more common among youths who describe themselves as too fat than those who describe themselves as about the right weight.

The derived demand for cigarettes has important implications for tax policy. Under reasonable assumptions, the demand for cigarettes is less price elastic among those who smoke for weight control. Thus, taxes on cigarettes will result in less behavior change (but more revenue collection and less deadweight loss) among those for whom the demand for cigarettes is a derived demand. Public health efforts to reduce smoking initiation and encourage cessation may wish to design campaigns to alter the derived nature of cigarette demand, especially among adolescent girls.
\end{abstract}

\author{
John Cawley \\ 3M24 MVR Hall \\ Department of Policy Analysis and Management \\ and Department of Economics \\ Cornell University \\ Ithaca, NY 14853 \\ and NBER \\ jhc38@cornell.edu
}

Stephanie von Hinke Kessler Scholder

Department of Economics and Related Studies

University of York

Heslington, York, YO10 5DD, UK

Stephanie.Scholder@york.ac.uk 


\section{Introduction}

Tobacco use is the number one preventable cause of death in the United States, responsible for an estimated 467,000 deaths in 2005 (Danaei et al., 2009). It is also associated with significant medical care costs. For example, smoking at age 24 is associated with lifetime medical expenditures that are \$3,757 higher for women and \$2,617 higher for men (Sloan et al., 2004). There are also substantial externalities associated with smoking, which amount to \$6,201 over the lifecycle, or \$1.44 per pack of cigarettes (Sloan et al., 2004).

As a result, there is tremendous interest in better understanding the demand for cigarettes (Chaloupka and Warner, 2000). One view, from public health, is that cigarettes are simply nicotine delivery vehicles, and that individuals smoke because they are addicted to nicotine and are trying to maintain optimum levels of the drug (see, e.g. British Medical Journal, 1977). This paper investigates a more economic explanation, which is that, for some groups, the demand for cigarettes is derived from the demand for weight control. The demand for a good is considered to be derived if the good is demanded as an input into the production of another thing of value. The classic example is that a firm's demand for capital, labor, and materials is derived from its desire to earn profits by selling market outputs that are produced with those inputs (Marshall, 1920).

Derived demand is relevant for many risky health behaviors. For example, a teenager's suicide attempt may be derived from a desire for attention or a wish to punish one's parents or boyfriend/girlfriend (Cutler, Glaeser and Norberg, 2001). Other examples include: teenage girls’ demand for sex, which may be derived from her desire to keep her boyfriend; and teenagers' demand for drugs and alcohol, which may be derived from a desire for peer acceptance (Kenkel, 2006; Cawley, 2008).

This paper makes three important contributions to the literature. First, we provide direct 
evidence from two large, nationally representative U.S. samples as to whether consumers demand cigarettes for the purposes of weight control. Specifically, we analyze data on adolescents from the Health Behavior in School-aged Children surveys and data on adults from the National Health and Nutrition Examination Surveys. These surveys are ideal for answering this question because they directly ask whether individuals are smoking for the purpose of controlling their weight. Second, we provide evidence regarding whose demand for cigarettes is derived from a demand for weight loss. Third, we discuss the implications of our findings for tax policy and anti-smoking campaigns more generally.

To preview our results, the data for youths indicate that roughly $5 \%$ of teenagers smoke as a form of weight control. However, conditional on being a frequent smoker, $46 \%$ of girls and $30 \%$ of boys report smoking for weight control. Smoking for weight control is particularly common among white girls and those who consider themselves too fat. Among adults, we find that less than $1 \%$ report smoking to control their weight, and these individuals also represent a small percentage of frequent smokers. We conclude with a discussion of the implications of these findings for tax policy and antismoking campaigns.

\section{The Interaction between Weight and Smoking}

Interestingly, for the demand for cigarettes to be derived from the demand for weight control, it is not necessary that smoking reduce weight. It is only necessary for consumers to believe that smoking reduces weight, and to demand cigarettes for that reason.

However, there is strong evidence from medical research that smoking does in fact promote weight loss. A review of the medical literature concludes that smoking increases energy expenditure by raising the metabolic rate: smoking a single cigarette is estimated to induce a 3\% rise in energy expenditure within 30 minutes (Chiolero et al., 2008). Moreover, there is strong evidence that nicotine suppresses the appetite (Mineur et al., 2011; Chiolero et 
al., 2008). Thus, smoking reduces weight both by increasing energy expenditure and decreasing energy intake. In fact, a recent commentary in the medical journal Diabetes stated that "smoking is one of the easiest and most reliable approaches to weight loss, at least for low-level smokers (<= 10 cigarettes/day)” (Novak and Gavini, 2012).

As a result, those who quit smoking tend to gain an average of 4-5 kg within 10 years of quitting (Flegal et al., 1995). The prospect of gaining weight may discourage smokers from even attempting to quit. In addition, weight gain after quitting increases the risk of smoking relapse (Chiolero et al., 2008). Thus, a desire to avoid weight gain may not only increase smoking initiation but also decrease quit attempts and decrease the probability of success among those trying to quit.

An economic literature investigates the link between cigarette taxes and obesity in the U.S., hypothesizing that higher cigarette taxes reduce smoking, with the unintended consequence of raising weight. The majority of these studies conclude that higher cigarette taxes are associated with higher body mass index (BMI) or rates of obesity (e.g. Chou, Grossman, and Saffer, 2004; Rashad, Grossman, and Chou, 2006; Baum, 2009), but other studies find no correlation between cigarette taxes and BMI or obesity (Gruber and Frakes, 2005; Nonnemaker et al. 2009). To some extent, the difference in results may be driven by differences in the way the studies control for time trends (Baum, 2009; Nonnemaker et al., 2009). Fang, Ali and Rizzo (2009) use local cigarette prices as an instrument for smoking status and conclude that smoking reduces body mass index, in particular for those in the healthy-weight range.

The cigarette industry is aware that the demand for its products may be derived from the demand for weight control. Tobacco industry documents released during the Master Settlement Agreement reveal that cigarette manufacturers realized that consumers consider smoking to be an appetite suppressant. In fact, they marketed cigarettes to promote that 
belief, and added appetite suppressants (such as tartaric acid) to cigarettes to reinforce that notion (Gonseth et al., 2012).

Cigarette marketing reflecting this derived nature of cigarette demand appeared as early as the 1920s (Amos and Haglund, 2000), when Lucky Strike ran the ad campaign "Reach for Lucky instead of a sweet”, which featured attractive women shadowed by obese silhouettes with the caption: "Is this you five years from now? When tempted to over-indulge, reach for a Lucky instead.”2 This ad campaign was so effective that it led to an advertising war in which the cigarette industry distributed information about the health risks of overeating and the candy industry counterattacked by distributing information about the health risks of smoking (Wagner, 1929; Calfee, 1986). The Federal Trade Commission ended the conflict by prohibiting tobacco companies from advertising cigarettes as a "reducing aid”, even by implication (Whelan, 1984, pp. 62-63).

While there is abundant evidence that both adults and youths, and especially girls, believe that smoking helps control weight (see e.g. Camp et al., 1993; Boles and Johnson, 2001; U.S. DHHS, 1988), it is unclear to what extent people smoke for that reason. The evidence that exists is indirect and only suggestive. Several studies have found that girls who are heavier, or are concerned about their weight, are more likely to smoke (Voorhees et al., 2002; Wee et al., 2001; Tomeo et al., 1999; Wiseman et al., 1998; French et al., 1994). Those studies report correlations, but three economic studies (each using a different dataset) suggest that the relationship is causal for teenage girls (Cawley, Markowitz and Tauras, 2004; Cawley, Markowitz and Tauras, 2006; Rees and Sabia, 2010). Exploiting the heritable component of weight as a natural experiment in longitudinal data, these studies find that a higher baseline weight increases the probability that teenage girls (but not boys) initiate smoking by the next survey wave.

\footnotetext{
${ }^{2}$ Cigarette companies' desire to exploit the derived nature of cigarette demand is also apparent in the names of certain brands, such as Trims and Virginia Slims.
} 
However, even these studies are unable to answer why girls who are heavier, or more concerned about their weight, are more likely to smoke or initiate smoking. The logical hypothesis is that such girls demand cigarettes for weight control, but the little direct evidence on this comes from small and unrepresentative samples. For example, Crisp et al. (1998) found that roughly $20 \%$ of a sample of smoking schoolgirls in London ( $\mathrm{N}=365)$, and roughly $34 \%$ of a sample of smoking schoolgirls in Ottawa $(\mathrm{N}=125)$ reported that they “definitely” smoked "instead of eating” and because it "makes me less hungry.” Camp et al. (1993) surveyed 659 students in two Catholic high schools in Memphis and found that 39\% of regular female smokers and $12 \%$ of regular male smokers reported smoking as a weight control strategy, while not a single black male or female smoked for that reason. Finally, Klesges and Klesges (1988) surveyed 1,076 students, faculty and staff at a large university in the southern U.S. and found that $32.5 \%$ of all smokers reported using smoking as a weight loss strategy. This study contributes to the literature by examining direct evidence of the derived demand for cigarettes using two nationally representative datasets.

\section{Data and Methods}

The two datasets examined here are the Health Behavior in School-Aged Children (HBSC) and the National Health and Nutrition Examination Surveys (NHANES). The HBSC is a cross-national study coordinated by the World Health Organization to gain insight into the health and well-being of youth (US D.H.H.S., 2003). HBSC collects data for a sample of 1,500 school children in each of three age groups: 11,13 and 15 years. Children are selected using a clustered sampling design, in which the initial sampling unit is the school class. Data are collected through self-administered questionnaires completed in the classroom.

We examine HBSC data for the United States for 2001-02 and 2005-06, when the survey included questions on weight control strategies. In addition to the sample of 11, 13 and 15

year olds, the U.S. sample was expanded to provide a nationally representative sample of $6^{\text {th }}$ 
to $10^{\text {th }}$ graders, aged 11-16 (US D.H.H.S., 2005).

Respondents to the HBSC self-report their weight and height. Self-reports of weight and height by adolescents are characterized by reporting error, but are considered of sufficiently high quality for use in research (see, e.g. Goodman et al., 2000; Brener et al., 2003a). We use these weights and heights to calculate their BMI and classify respondents as underweight, healthy weight, overweight, or obese using growth charts from the Centers for Disease Control and Prevention (U.S. D.H.H.S, 2002). Respondents also report the perception of their body weight: when asked “Do you think your body is...”, they respond with one of the following: “much too thin”, “too thin”, “about right”, “a bit too fat”, or “much too fat.”

The HBSC asks: “How often do you smoke cigarettes as present?” Respondents are coded as smokers if they answer “every day,” “at least once a week, but not every day,” or "less than once a week" and are coded as non-smoker if they respond "I do not smoke." When we examine smoking frequency, we combine the first two responses, leaving three categories: "at least once a week," "less than once a week," and "do not smoke”. Furthermore, the HBSC asks respondents about the type of weight control behaviors they engage in. For our purposes, a key question is: "Which of the following things did you do to control your weight during the last 12 months?” to which one possible answer is “smoke more.”

The full HBSC sample includes 14,817 students in 2001-02 and 9,227 students in 200506. However, questions about individual's weight control behaviors were not asked of middle school children in 2001-02, and were only asked of half of the sixth graders in 200506. Hence, our sample includes 14-16 year old high school students in grades 9 and 10 in 2001-02 ( $\mathrm{n}=5,226)$ and 12-16 year old middle and high school students in grades 6 to 10 in 2005-06 $(n=7,690)$. To ensure the same sample is used in all analyses, we drop those with missing data on smoking behaviors, weight, height, and weight perception, resulting in a final 
sample of 10,442 students (4,113 in 2001-02 and 6,329 in 2005-06).

We also analyze data on adult respondents to the National Health and Nutrition Examination Survey (NHANES) Continuous. In the 2005-06, 2007-08, and 2009-10 NHANES, respondents who reported that they tried to lose weight or did something to keep from gaining weight in the past 12 months are asked: "How did you try to lose weight?" Among the optional answers is: "Started to smoke or began to smoke again." Note that the wording is different from that in the HBSC, as it asks about the extensive margin (initiation) rather than the intensive margin; we discuss the implications of this below.

The NHANES asks: “Do you now smoke cigarettes?” Respondents are coded as smokers if they respond "every day” or "some days” and are coded as non-smokers if they respond "not at all."

We utilize three weight-related measurements in NHANES: (1) weight and height recorded by medical professionals during the medical examination of respondents, (2) respondents' perception of their weight (“How do you consider your weight”), where they responded either "underweight”, “about the right weight”, or “overweight”, and (3) respondents' weight preferences, as indicated by the question "Would you like to weigh more, less, or stay about the same?”.

The full NHANES sample contains 10,348 respondents in 2005-06, 10,149 respondents in 2007-08, and 10,537 in 2009-10. We drop those who did not take a medical examination, those who are pregnant, and those younger than 16, as they were not asked about their weight control strategies. To ensure the same sample is used in all analyses, we drop those with missing data on current smoking, smoking for weight control, weight, height, weight perception, and weight preferences, resulting in a final sample of 15,744 respondents aged 16-85 years (4,345 in 2005-06; 5,505 in 2007-08; and 5,894 in 2009-10).

To examine the extent to which the demand for cigarettes is derived from the demand for 
weight control, we calculate the unconditional percentage of the sample that reports smoking to control their weight. To investigate which subgroups are most likely to demand cigarettes as a method of weight loss, we estimate probit regressions of smoking for weight loss as a function of BMI classification, weight perception, age, year, race and maternal socioeconomic status (SES) based on her occupation category. We classify maternal occupations categorized as professional or business as high SES; occupations categorized as technical, office or skilled as medium SES; and those categorized as service or laborer as low SES. We estimate all models separately by gender. Because HBSC respondents are selected using a clustered sampling design, we cluster standard errors at the school level to account for any correlation in error terms among children in the same school. All descriptive statistics and analyses are weighted by the sample weights provided by the surveys.

\section{Results}

Table 1 presents descriptive statistics for the explanatory variables in the HBSC sample. The prevalence of obesity (based on self-reported weight and height) is lower for girls (9.4\%) than boys (14.9\%). However, describing oneself as "much too fat" is more than twice as common among girls (5.8\%) than boys (2.3\%).

Table 2 presents descriptive statistics for the explanatory variables in the NHANES sample. The prevalence of obesity (based on measured weight and height) is roughly onethird for both women (35.7\%) and men (33.4\%). There is a gender difference, however, in the percent of NHANES respondents who describe themselves as overweight: $63.6 \%$ for females and $50.2 \%$ for males.

Table 3 (for HBSC) and Table 4 (for NHANES) present descriptive statistics for smoking variables, showing the proportions of individuals who are current smokers, and who smoke for weight control by gender. The first row of Table 3 indicates that, in the HBSC, 
girls are significantly less likely than boys to smoke (15.1\% vs. $17.5 \%)$, but the second row shows that smoking for weight control is more common among girls (5.3\%) than boys (4.8\%), though this difference is not statistically significant.

Subsequent rows in Table 3 show differences in the tendency to smoke for weight control by age, grade, race, smoking frequency, weight classification and weight perception. Smoking for weight control is more likely among older than younger girls; e.g. it is reported by $6.7 \%$ of 16 -year-olds compared to $1.8 \%$ of 13 -year-olds. Among girls, smoking for weight control is more than twice as likely for whites (6.6\%) than African-Americans (2.8\%, $\mathrm{p}<0.001$ ), whereas it is roughly equally likely for white (4.7\%) and African-American boys $(5.0 \%, p=0.738)$.

Table 3 also reveals that large fractions of frequent smokers (defined as those who smoke at least once per week) report that they smoke to control their weight; this is true of $46.4 \%$ of female frequent smokers and $30.0 \%$ of male frequent smokers. Thus, although only $5.3 \%$ of girls and $4.8 \%$ of boys smoke to control their weight, they represent large percentages of the youth whose smoking is a serious public health concern.

The final rows of Table 3 present the proportion of respondents who smoke to control their weight by weight classification (calculated using their weight and height) and the individual's perception of their weight. Among girls, the overweight and obese are more likely than the healthy weight to report smoking to control weight, but the difference is not statistically significant. However, a girl's perception of her weight does predict smoking to control weight: girls who describe themselves as "much too fat" and "too fat" are more likely to smoke for weight control than girls who describe themselves as "about right" (15.7\% and $6.8 \%$ respectively versus $3.3 \%)$.

Among boys, the obese are significantly more likely to smoke for weight control than the healthy weight (7.5\% versus $4.4 \%$ ). Similarly, boys who describe themselves as "much too 
fat” are significantly more likely to smoke for weight control than those who describe themselves as “about right” (10.5\% versus $4.1 \%)$.

These findings are consistent with derived demand; youth who are, or believe themselves to be, overweight are more likely to smoke for weight control. However, an unexpected result in Table 3 is that the underweight are also more likely to report smoking for weight control. Among girls, those who describe themselves as "much too thin" are significantly more likely than girls who say they are "about right” to smoke for weight control $(10.9 \%$ versus 3.3\%), though there is not a difference between girls whose BMI is in the underweight as opposed to healthy weight category (even though BMI is calculated using self-reported weight that may reflect perceptions). For boys, those who perceive themselves to be "much too thin" are more likely than those who perceive themselves to be "about right" to smoke for weight control (8.9\% versus $4.1 \%$ ), and those whose self-reported weight and height is in the underweight range are significantly more likely to report smoking for weight control than those in the healthy weight range (8.5\% versus $4.4 \%)$. We discuss this surprising finding later in the paper.

Table 4 presents similar information for the sample of NHANES adults. The prevalence of smoking among NHANES adults (19.9\% among women, 25.3\% among men) is higher than that among HBSC teenagers (15.1\% among girls, $17.5 \%$ among boys). However, the prevalence of smoking to control weight is much lower among NHANES adults $(0.6 \%$ of women, $0.3 \%$ of men) than among HBSC teenagers (5.3\% of girls, $4.8 \%$ of boys). This is likely in part due to the difference in question wording (the HBSC asked whether respondents smoke more to control their weight, and the NHANES asks whether they started to smoke or began to smoke again to control their weight).

Even among daily smokers in the NHANES, very few report smoking to control their weight (1.0\% of men and $2.7 \%$ of women). However, there is evidence of the derived nature 
of cigarette demand. For both men and women, respondents who report they would like to weigh less are six to eight times more likely to report smoking for weight control than respondents who say they would like to weigh the same, and the differences are statistically significant for both genders. In addition, men who are obese are significantly more likely than healthy weight men to smoke for weight control ( $0.6 \%$ versus $0.1 \%)$. The practice is also significantly more common among men who describe themselves as overweight than men who describe themselves as about right ( $0.5 \%$ versus $0.1 \%)$.

To investigate in more detail who has a derived demand for cigarettes, we estimate probit regressions of smoking to control one's weight, as a function of observable characteristics. Models are estimated using the HBSC data. Because of the small percentage of NHANES respondents who report smoking to control their weight (47 out of 7,915 females and 25 out of 7,829 males), we do not estimate regression models for the NHANES.

Table 5 presents the marginal effects of probit regressions of smoking for weight control on one of three measures of weight (BMI, BMI classification and weight perception) plus demographic characteristics, estimated using the full HBSC sample (i.e. not just smokers).

Among girls, each additional unit of BMI is associated with a 0.2 percentage point higher probability of smoking for weight control (column 1). Although the probability that a girl smokes for weight control rises with weight classification, the differences in point estimates are small and are not statistically significant (col. 2). In contrast, a girl's perception of weight is strongly and significantly correlated with the probability of smoking for weight control (col. 3). Girls who describe themselves as “a bit too fat” are 2.9 percentage points more likely to smoke for weight control, and those who describe themselves as "much too fat” are 11.9 percentage points more likely to engage in the practice compared to those who describe themselves as "about right”. Given that only 5.3\% of girls in the sample smoke for weight control, these magnitudes are substantial. As was found in the unconditional results 
of Table 3, girls who describe themselves as “much too thin” are also significantly more likely to smoke for weight control than girls who describe their weight as "about right" (moreover, the point estimate is large: 8.4 percentage points). Another finding of interest is that African American girls are 2.4 to 3.0 percentage points less likely to smoke for weight control than otherwise identical white girls.

Among boys, we find that the obese are 2.8 percentage points more likely to smoke for weight control than healthy-weight boys, and that boys who describe themselves as "much too fat” are 6.9 percentage points more likely to smoke for weight control than boys who describe their weight as "about right” (col. 6). The practice is more likely among the older boys in the sample, but no other observable characteristics significantly predict the practice.

The differences in the predictive power of weight classification and weight perception, especially for girls, beg the question of how the two differ. Table 6 presents cross-tabulations for girls and boys. Even though clinical weight classification is based on self-reported weight and height, and thus may be biased by the respondent's perception of their weight, there is considerable variation of perceptions within weight classifications. Among healthy weight girls, $1.3 \%$ describe themselves as "much too thin," $9.1 \%$ say they are "too thin," $60.2 \%$ describe themselves as “about right,” 27.2\% say they are “a bit too fat,” and 2.3\% describe themselves as "much too fat." 3 The percentage of girls who report that they are "much too fat” constitute $0.6 \%$ of the underweight, $2.3 \%$ of the healthy weight, $9.3 \%$ of the overweight, and $29.0 \%$ of the obese. The substantial variation in perceptions within weight classification explains how smoking for weight control can be more strongly correlated with girls’ perceptions of their weight than their clinical weight classification.

When we regress smoking for weight control on clinical weight classification and weight

\footnotetext{
${ }^{3}$ Variation in weight perception within weight classification is likely due in part to the fact that BMI is a poor measure of fatness, because it does not distinguish between fat from muscle. Thus, the overweight category includes people who are fat for their height (and may perceive themselves as too fat) as well as those who are muscular for their height (and may perceive their weight as about right); see Burkhauser and Cawley (2008).
} 
perception (not shown here; available from the authors upon request), weight perception but not clinical weight classification is statistically significant. From this, we conclude that a girl's perception of her weight is a stronger predictor of whether she smokes for weight control than her self-reported weight and height. When we estimate such a regression for boys, coefficients on both weight classification and weight perception variables are close to zero, with none statistically significant.

\section{Extension: How do those who smoke for weight control differ from those who smoke for other reasons?}

We investigate how those who smoke for weight control differ from those who smoke for other reasons by estimating probit regressions of smoking for weight loss on observable characteristics, using only the sample of smokers in the HBSC. We again estimate separate regressions for each of the three sets of weight variables: BMI, weight classification based on BMI, and weight perceptions.

Table 7 presents the marginal effects from these probit regressions. Among girls who smoke, those who describe themselves as a "bit too fat” are 14.1 percentage points more likely, and those who describe themselves as "much too fat" are 26.8 percentage points more likely, to smoke for weight control, compared to those who consider themselves to be "about right” (col. 3). Among girls who smoke, smoking for weight control is between 12.8 and 16.1 percentage points less likely among African-Americans than whites.

Among boys who smoke, smoking for weight control is 9.0 percentage points more likely among the obese, but 9.2 percentage points less likely among the overweight, relative to the healthy weight (col. 5). However, we also find that, among boys who smoke, the underweight are 32.1 percentage points more likely to do so for weight control. 


\section{Extension: How do those who smoke for weight control differ from those who use other methods to control their weight?}

The HBSC and NHANES each asked respondents about a host of strategies one can use to control one's weight. The prevalence of each method is detailed in Table A.1 (HBSC) and Table A.2 (NHANES) in Appendix A. These tables show that healthy weight control behaviors, such as exercising, eating more fruit and vegetables, and eating fewer sweets are much more common weight loss behaviors than smoking. They are also much more common than other unhealthy methods of weight loss, such as using diet pills or laxatives, and vomiting. For example, in the HBSC, 84.8\% of girls report exercising to control their weight,

and $62.8 \%$ report eating fewer sweets, compared to $5.7 \%$ who report vomiting, and $5.3 \%$ who report smoking as a method of weight loss. More generally, over $90 \%$ of HBSC respondents "have gone on a diet, changed their eating habits, or done something else to control their weight during the last 12 months” (not shown in Table, available upon request).

The lower panel of Table A.1 shows the proportion of the HBSC sample who engage in each of these strategies, conditional on smoking to control weight. The conditional means of (e.g.) exercise, eating fewer sweets and less fat are relatively similar to the unconditional means in the upper panel of the table. In other words, it does not appear to be the case that those who smoke for weight control are less likely to exercise or eat healthy. In other words, smoking does not appear to be a substitute for healthy methods of weight control. However, the prevalence of unhealthy behaviors is substantially more common among those smoking for weight control than for the sample as a whole. For example, $38.7 \%$ of girls and $33.8 \%$ of boys who smoke for weight control also report taking diet pills or laxatives, compared to $6.7 \%$ and $3.3 \%$ of girls and boys in the full sample. Vomiting for weight loss is practiced by $27.6 \%$ of girls and $27.1 \%$ of boys who smoke for weight loss, compared to $5.7 \%$ of girls and $2.7 \%$ of boys in the sample as a whole. Fasting is practiced by $42 \%$ of girls and $27.5 \%$ of 
boys who smoke to control their weight, compared to $17.7 \%$ and $7.3 \%$ of girls and boys in the full sample. Thus, those engaged in the already-risky and unhealthy practice of smoking for weight control are more likely to be engaged in a constellation of other risky weight control behaviors, which is troubling from a public health perspective.

A comparison of the prevalence of weight control strategies among youth in the HBSC (Table A.1) and adults in the NHANES (Table A.2) indicates that both healthy and unhealthy weight control strategies are much less common in the adult sample. Only $37.3 \%$ of women and $29.4 \%$ of men exercise to control their weight, compared to $84.8 \%$ of girls and $84.2 \%$ of boys in the HBSC sample. Similarly, $24.6 \%$ of women and $17.3 \%$ of men in the NHANES report eating less fat, compared to $58.9 \%$ of girls and $42.9 \%$ of boys in the HBSC. Only a small proportion of adults report practicing unhealthy weight control behaviors such as smoking $(0.6 \%$ or women and $0.3 \%$ of men), or taking laxatives or vomiting $(0.5 \%$ of women and $0.2 \%$ of men). The proportion of individuals engaging in each weight control behavior is higher among those smoking for weight control (lower panel of Appendix Table A.2) than for the sample as a whole (the upper panel of the same table). However, as shown in the last row of Table A.2, these comparisons rely on very small samples and should not be overinterpreted.

To further investigate how those who smoke for weight control differ from those who use other methods to control their weight, we estimate a probit regression for smoking for weight control on observables, restricting the HBSC sample to those who report attempting to control their weight (through any means). Results are presented in Table 8. Even within the set of people trying to control their weight, we find that those who perceive themselves as “much too fat” are more likely to smoke for weight loss (11.7 percentage points more likely for girls, 7.0 percentage points more likely for boys). Moreover, boys with a BMI in the obese range are 2.4 percentage points more likely to smoke to control their weight. In 
general, with the majority of people in the HBSC sample indicating to have tried to control their weight in the last 12 months, the results are very similar to those based on the full sample of HBSC respondents (Table 5). Thus, also among those trying to control their weight, heavier individuals are more likely to smoke to achieve that end. This is not a linear relationship, however; we once again find that girls who say they are “much too thin” (yet are still trying to lose weight) are significantly more likely to smoke as a method of weight control than girls who say their weight is "about right."

\section{Discussion}

This paper contributes to the economic literature on the demand for cigarettes by demonstrating that the demand for cigarettes is, for some individuals, derived from the demand for weight control. The data presented in this paper, the HBSC for youths and the NHANES for adults, provide the most direct evidence to date, because both explicitly ask respondents whether they smoke to control their weight. Overall, a modest percentage of youth smoke as a form of weight control: $5.3 \%$ of girls and $4.8 \%$ of boys. However, among frequent smokers, $46.4 \%$ of girls and $30.0 \%$ of boys report smoking for weight control. In contrast, less than $1 \%$ of adults smoke to control their weight, and they also represent only a small percentage of frequent smokers (2.7\% of women, $1.0 \%$ of men). Regressions indicate that smoking for weight control is particularly common among youths who describe themselves as too fat, and is less likely among African-American girls than white girls.

There are two possible reasons why this evidence is stronger in the HBSC than in the NHANES. The first is that the cigarette demand of teenagers (especially girls) may be more likely to be derived than that of adults. For example, girls may be more concerned than adult women with their weight and appearance. The age pattern could also be explained by people learning with age that smoking is an unwise method of weight loss. 
A second reason is the difference in the wording of the question. The HBSC asks whether youths "smoked more" to lose weight, whereas the NHANES asks adults whether they "started to smoke or began to smoke again.” Increasing consumption on the intensive margin (smoking more) may simply be more common than increasing consumption on the extensive margin (initiation).

We find that perception of weight is a stronger predictor of smoking for weight control among girls than boys. For example, reporting that one is "much too fat" is associated with a 11.9 percentage point higher probability of smoking to control weight for girls, compared to a 6.9 percentage point higher probability for boys. Reporting that one is a "bit too fat" is associated with a 2.9 percentage point increase in smoking for weight control by girls, but an insignificant 1.4 percentage point increase for boys. This gender difference is consistent with a large body of evidence that the labor market and social consequences of being overweight or obese are greater for women than men: obese women are more likely than obese men to be socially stigmatized (Puhl, 2011), develop obesity-related depression (Granberg, 2011), or suffer labor market penalties such as lower wages (Averett, 2011; Cawley, 2004). Given that the costs of heaviness are greater for women, they may be willing to pay a higher price and take greater risks for weight control and reduction. For example, even though the prevalence of obesity in the U.S. is almost identical for women (35.8\%) and men (35.7\%) (Flegal et al., 2012), there is a large difference in the proportion trying to lose weight: $60 \%$ of women and 36\% of men (Baradel et al., 2009).

We find that African-American girls are between 2.4 and 3.0 percentage points less likely than white girls to smoke to control their weight. This too is consistent with differences in the costs of overweight and obesity. Obese African-American women report being more satisfied with their appearance and are less likely to suffer obesity-related depression, social stigmatization or employment discrimination than obese white females 
(Granberg, 2011; Puhl, 2011; Averett, 2011).

An unexpected finding, however, is that those who perceive themselves to be underweight are also more likely to report smoking for weight control. Among both girls and boys, those who describe themselves as "much too thin" are significantly more likely than those who describe their weight as "about right" to smoke for weight control. One possible explanation is that smoking is an extremely effective method of weight loss, and, absent smoking, these underweight individuals would be much heavier, so they accept being too thin as the lesser of two evils. However, this does not necessarily hold for girls, as it is only those who perceive themselves to be underweight, rather than those who actually are underweight, who smoke for weight control. (Among boys, both underweight and the perception of being "too thin" predict smoking for weight control). Exploring this finding is an interesting direction for future research.

The findings of this paper are relevant for cigarette tax policy and understanding heterogeneity in consumer response to prices. Specifically, our findings suggest that the Hicks-Marshall laws of derived demand (Marshall, 1920; Bronfenbrenner, 1961) apply to teenage girls’ price elasticity of the demand for cigarettes. The Hicks-Marshall laws were originally derived to explain the wage elasticity of a firm's demand for labor, but the laws generalize to any other case of derived demand. The laws state the following conditions under which a derived demand will be relatively price inelastic: 1) the demand for the ultimate objective is relatively price inelastic; 2) the input is essential to the production of the objective, i.e. there are no easy substitutes for the inputs; and 3) expenditures on the input are a relatively small fraction of the total cost of the ultimate objective (this is sometimes referred to as the importance of being unimportant).

In the context of the demand for cigarettes being derived from the demand for weight control, there is evidence supporting each of the Hicks-Marshall conditions. The first 
condition may be satisfied because losing weight, or avoiding weight gain, is considered important among females and especially among white adolescent females (Puhl, 2011; Granberg, 2011). As a result, teenage girls’ demand for a slim appearance may be highly inelastic. The second condition may be satisfied because the vast majority of weight loss attempts fail (e.g. Crawford et al., 2000). Therefore, people may perceive that there are relatively few substitutes for cigarettes as a means of suppressing appetite. Teenage girls in particular may not have access to alternative methods of weight loss, such as prescription weight loss drugs or bariatric surgery. Recall that "smoking is one of the easiest and most reliable approaches to weight loss, at least for low-level smokers” (Novak and Gavini, 2012). Moreover, teenage girls may consider losing weight by smoking to be more enjoyable than losing weight through exercise or diet. Finally, although cigarettes are relatively expensive, the third condition may be satisfied because a substantial fraction of the cigarettes smoked by youth are not purchased by them. For example, Forster et al. (2003) find that only $16 \%$ of teenage smokers paid for the last cigarette they smoked; the remainder had bummed them from friends or stolen them from others (e.g. parents). Similarly, 34\% of respondents to the Youth Risk Behavior Surveillance System said that their usual source of cigarettes was to borrow them (Katzman et al., 2007). Overall, the Hicks-Marshall laws of derived demand appear to apply, which suggests that those who demand cigarettes for weight loss (e.g. teenage girls who perceive themselves as too fat) may be relatively inelastic to cigarette prices and taxes.

Although only $5.3 \%$ of girls and $4.8 \%$ of boys smoke to control their weight, $46 \%$ of girls who smoke frequently, and $30 \%$ of boys who smoke frequently, engage in that practice. This is relevant for tax policy because it is the frequent smokers who impose the greatest costs, and thus it is their behavior that public health most wants to modify.

The decreased sensitivity to prices and taxes suggests that other policies may be more 
effective in reducing smoking among teenage girls. As a result of the Family Smoking Prevention and Tobacco Control Act of 2009, the FDA now has regulatory authority over tobacco and cigarette advertising. As shown in internal documents from the tobacco industry (e.g. Gonseth et al., 2012), cigarette companies have historically advertised in such a way as to encourage consumers to use cigarettes to control their weight. The FDA may wish to consider using its new authority over cigarette advertising to ensure that industry does nothing to reinforce the derived nature of cigarette demand.

Public health campaigns to deter smoking initiation may wish to consider addressing the link between smoking and weight control, and smoking cessation messages may wish to address smokers' concerns that quitting would result in weight gain. However, the wording and design of such messages is important; they may make people aware of the possibility that smoking can be used as a method of weight control and thereby unintentionally increase smoking initiation. Historically, some poorly-designed public health messages have backfired and had the opposite effect than was intended (Byrne and Neiderdeppe, 2011). In principle, the recognition that the demand for cigarettes is partly derived from the demand for weight loss can be used to craft more effective messages to prevent smoking initiation and encourage smoking cessation.

By clarifying the link between obesity and smoking, this paper contributes to the larger economic literature on interactions between risky health behaviors, for example: gateway and stepping stone effects (e.g. Pacula, 1997; van Ours, 2003), the complementarity of alcohol and tobacco (e.g. Dee, 1999), and the substitutability of alcohol and marijuana (e.g. DiNardo and Lemieux, 2001). In general, such interactions between risky health behaviors are an interesting and promising direction for future research.

There are several limitations of our data. The HBSC includes only self-reported, not measured, weight and height, and thus there is an unknown degree of reporting error that 
results in misclassification into weight categories such as overweight and obese. However, studies of this error conclude that self-reported weight and height by youths are of sufficiently high quality for use in research (Goodman et al., 2000; Brener et al., 2003a). Another limitation is that BMI, and clinical weight classifications based on BMI, are imperfect measures of fatness in that they ignore body composition - they do not distinguish fat from muscle (Burkhauser and Cawley, 2008); this may explain why we find differing results for weight classification based on BMI and the respondent's perception of their weight. Unfortunately, the HBSC does not contain direct or objective measures of fatness, only self-reported weight and perception of own weight, so we are limited to using those measures.

Smoking status is also self-reported and thus may contain error, but the HBSC was welldesigned to collect such information, as it was self-administered (versus administered by an interviewer) and conducted in the classroom (as opposed to the home); both of these survey characteristics have been found to yield more accurate reports of risky behaviors by youths (Brener et al., 2003b).

This investigation into the derived nature of cigarette demand offers several directions for future research. First, it is important to measure the price elasticity of cigarette demand among teenage girls who do and do not demand cigarettes for weight control, in order to determine the effectiveness of cigarette taxes in deterring smoking for these groups. Second, future research could investigate the extent to which the demand for cigarettes is derived from the demand for still other things, such as peer acceptance. Third, future studies could examine the extent to which incorporating derived demand into economic models improves our understanding of other risky behaviors, such as unprotected sex, alcohol consumption, drug use, and suicide. Finally, an important direction for future research is to determine how advertising can create or strengthen a derived demand, by making the advertised good seem 
like a necessary input into the production of things that that the consumer values, such as peer acceptance, coolness, and attractiveness. 


\section{References}

Amos, A. and Haglund, M., 2000. From Social Taboo to "Torch of Freedom”: The Marketing of Cigarettes to Women. Tobacco Control 9, 3-8.

Averett, Susan L. 2011. "Labor Market Consequences: Employment, Wages, Disability, and Absenteeism.” In: John Cawley (editor), Handbook of the Social Science of Obesity. (Oxford University Press: New York).

Baradel, Lesley A., Cathleen Gillespie, Jana R. Kicklighter, Michele M. Doucette, Meera Penumetcha, Heidi M. Blanck. 2009. “Temporal changes in trying to lose weight and recommended weight-loss strategies among overweight and obese Americans, 19962003.” Preventive Medicine 49: 158-164.

Baum, C.L. The effects of cigarette cost on BMI and obesity. Health Economics 18, 3-19.

Boles, S. and Johnson, P., 2001. Gender, Weight Concerns and Adolescent Smoking. Journal of Addictive Diseases 20 (2), 5-14.

Brener, Nancy D., Tim McManus, Deborah A. Galuska, Richard Lowry, Howell Sechsler. 2003a. "Reliability and Validity of Self-reported Height and Weight Among High School Students.” Journal of Adolescent Health, 32: 281-287.

Brener ND, Billy JOG, Grady WR. 2003b. “Assessment of Factors Affecting the Validity of Self-Reported Health-Risk Behavior Among Adolescents: Evidence From the Scientific Literature.” Journal of Adolescent Health, 33: 436-457.

British Medical Journal. 1977. “Do People Smoke for Nicotine?” (6094): 1041-1042.

Bronfenbrenner, M. 1961. "Notes on the Elasticity of Derived Demand." Oxford Economic Papers, 13(3): 254-261.

Burkhauser, Richard V., and John Cawley. 2008. "Beyond BMI: The Value of More Accurate Measures of Fatness and Obesity in Social Science Research.” Journal of Health Economics, 27(2): 519-529.

Byrne, Sahara, and Jeff Niederdeppe. 2011. "Unintended Consequences of Obesity Prevention Messages.” In: John Cawley (editor), Handbook of the Social Science of Obesity. (Oxford University Press: New York).

Calfee, Jack E. 1986. “The Ghost of Cigarette Advertising Past.” Regulation, November/December, pp. 35-45.

Camp, D. et al., 1993). The Relationship between Body Weight Concerns and Adolescent Smoking. Health Psychology 12 (1), 24-32.

Cawley, John. "The Impact of Obesity on Wages." Journal of Human Resources, 2004, 39(2): 451-474.

Cawley, John. 2008. "Reefer Madness, Frank the Tank or Pretty Woman: To What Extent Do Addictive Behaviors Respond to Incentives?” Chapter 7 in: Frank Sloan and Hirschel Kasper (editors), Incentives and Choice in Health and Health Care, (MIT Press: Cambridge, MA).

Cawley, John, Sara Markowitz, and John Tauras. 2004. "Lighting Up and Slimming Down: The Effects of Body Weight and Cigarette Prices on Adolescent Smoking Initiation.” Journal of Health Economics 23, 293-311.

Cawley, John, Sara Markowitz, and John Tauras. 2006. "Body Weight, Cigarette Prices, Youth Access Laws and Adolescent Smoking Initiation.” Eastern Economic Journal, 32(1): 149-170.

Chaloupka, Frank J. and Kenneth E. Warner. 2000. “The Economics of Smoking.” In A.J. Culyer and J.P Newhouse (eds.) Handbook of Health Economics, Volume 1. (New York: Elsevier), pp. 1539-1628.

Chiolero, A., D. Faeh, F. Paccaud, and J. Cornuz. 2008. “Consequences of Smoking for 
Body Weight, Body Fat Distribution, and Insulin Resistance.” American Society for Clinical Nutrition, 87(4), 801-809.

Chou SY, Grossman M, Saffer H. 2004. "An economic analysis of adult obesity: results from the behavioral risk factor surveillance system.” Journal of Health Economics 23, 565-587.

Crawford, D., Jeffery, R.W. and French, S.A. 2000. “Can Anyone Successfully Control Their Weight? Findings of a Three Year Community-Based Study of Men and Women.” International Journal of Obesity, 24: 1107-1110.

Crisp, A. et al., 1998. Smoking and Pursuit of Thinness in Schoolgirls in London and Ottowa. Postgraduate Medical Journal 74:473-9.

Cutler DM, Glaeser EL, Norberg KE. 2001. "Explaining the Rise in Youth Suicide.” Chapter 5 in: Jonathan Gruber (editor), Risky Behavior among Youths: An Economic Analysis, pp. 219-270.

Danaei, Goodarz, Eric L. Ding, Dariush Mozaffarian, Ben Taylor, Jurgen Rehm, Christopher J. L. Murray, Majid Ezzati. 2009. “The Preventable Causes of Death in the United States: Comparative Risk Assessment of Dietary, Lifestyle, and Metabolic Risk Factors.” PLoS Med 6(4): e1000058. doi:10.1371/journal.pmed.1000058.

Dee, Thomas S. 1999. “The complementarity of teen smoking and drinking.” Journal of Health Economics, 18: 769-793.

DiNardo, John and Thomas Lemieux. 2001. “Alcohol, marijuana, and American youth: the unintended consequences of government regulation.” Journal of Health Economics, 20: 991-1010.

Fang H, Ali MM, Rizzo JA. 2009. "Does smoking affect body weight and obesity in China?” Economics and Human Biology, 7(3):334-50.

Flegal K.M., R.P. Troiano, E.R. Pamuk, R.J. Kuczmarski and S.M. Campbell. 1995. "The influence of smoking cessation on the prevalence of overweight in the United States." N Eng J Med, 333: 1165-1175.

Flegal, Katherine M., Margaret D. Carroll, Brian K. Kit, and Cynthia L. Ogden. 2012. "Prevalence of Obesity and Trends in the Distribution of Body Mass Index Among US Adults, 1999-2010.” JAMA, 307(5): E1-E7.

Forster, J., V. Chen, T. Blaine, C. Perry, and T. Toomey. 2003. "Social Exchange of Cigarettes by Youth.” Tobacco Control, 12: 148-154.

French, S. et al., 1994. Weight Concerns, Dieting Behavior, and Smoking Initiation among Adolescents: A Prospective Study. American Journal of Public Health 84 (11), 181820.

Gonseth, Semira, Isabelle Jacot-Sadowski, Pascal A. Diethelm, Vincent Barras, Jacques Cornuz. 2012. "The tobacco industry's past role in weight control related to smoking.” European Journal of Public Health, 1-5.

Goodman, Elizabeth, Beth R. Hinden, and Seema Khandelwal. 2000. “Accuracy of Teen and Parental Reports of Obesity and Body Mass Index.” Pediatrics, 106: 52-58.

Granberg, Ellen. 2011. "Depression and Obesity.” In: John Cawley (editor), Handbook of the Social Science of Obesity. (Oxford University Press: New York).

Gruber, J. and Frakes, M. 2006. Does falling smoking lead to rising obesity? Journal of Health Economics 25, 183-197.

Katzman, Brett, Sara Markowitz, and Kerry Anne McGeary. 2007. “An Empirical Investigation of the Social Market for Cigarettes,” Health Economics, 16(10): 102539.

Kenkel, Don. 2006. “Health behaviours among young people.” In: Andrew M. Jones (ed.), The Elgar Companion to Health Economics.

Klesges, R. \& Klesges L., 1988. Cigarette Smoking as a Dieting Strategy in a University 
Population. International Journal of Eating Disorders 7(3):413-9.

Marshall, Alfred. 1920. Principles of Economics, 8th Edition. (Philadelphia PA: Porcupine Press).

Mineur YS, Abizaid A, Rao Y, Salas R, DiLeone RJ, Gundisch D, Diano S, De Biasi M, Horvath TL, Gao X-B, Picciotto MR. 2011. "Nicotine Decreases Food Intake Through Activation of POMC Neurons.” Science, 332:1330-32.

Nonnemaker, J. et al. 2009. Have efforts to reduce smoking really contributed to the obesity epidemic? Economic Inquiry 47, 366-376.

Novak CM, Gavini CK. 2012. “Smokeless Weight Loss.” Diabetes, 61:776-777.

Pacula, Rosalie Liccardo. 1997. "Economic Modelling of the Gateway Effect.” Health Economics, 6: 521-524.

Puhl, Rebecca. 2011. "Bias, Stigma, and Discrimination.” In: John Cawley (editor), Handbook of the Social Science of Obesity. (Oxford University Press: New York).

Rashad, Inas, Michael Grossman and Shin-Yi Chou. 2006. "The Super Size of America: An Economic Estimation of Body Mass Index and Obesity in Adults," Eastern Economic Journal, 32(1), 133-148.

Rees, D. and J. Sabia. 2010. Body Weight and Smoking Initiation: Evidence from Add Health. Journal of Health Economics 29, 774-7.

Sloan, Frank A., Jan Ostermann, Christopher Conover, Donald H. Taylor, Jr. and Gabriel Picone. 2004. The Price of Smoking. MIT Press: Cambridge, MA.

Tomeo, C. et al., 1999. Weight Concerns, Weight Control Behaviors, and Smoking Initiation. Pediatrics 104 (4), 918-24.

US Department of Health and Human Services, 1988. The Health Consequences of Smoking: Nicotine Addiction: A Report of the Surgeon General. US Department of Health and Human Services, Centers for Disease Control, Center for Health Promotion and Eduation, Office of Smoking and Health, Publication No. CDC 888406. Rockville, MD

US Department of Health and Human Services. 2002. 2000 CDC growth charts for the United States: methods and development. Vital and National Health Statistics, Series 11, Number 246, May.

U.S. Department of Health and Human Services, 2003. Health Resources and Services Administration, Maternal and Child Health Bureau. Health Behavior in School-aged Children Survey, 2001-02 [Computer file]. Calverton, MD: ORC Macro (Macro International Inc.) [producer].

US Department of Health and Human Services, 2005. Health Behavior in School-Aged children, 2001-2002 [United States]. US Department of Health and Human Services. Health Resources and Services Administration. Maternal and Child Health Bureau.

Van Ours, Jan C. 2003. “Is cannabis a stepping-stone for cocaine?” Journal of Health Economics, 22: 539-554.

Voorhees, C. et al., 2002. Early Predictors of Daily Smoking in Young Women: The National Heart, Lung and Blood Institute Growth and Health Study. Preventive Medicine 34, 616-24.

Wagner, Philip. 1929. "Cigarettes vs. Candy: War Correspondence from a New Battle Front.” The New Republic, February 13, 1929, pp. 343-345.

Wee, C. et al., 2001. Relationship Between Smoking and Weight Control Efforts Among Adults in the United States. Archives of Internal Medicine 161, 546-50.

Whelan, E.M. 1984. The Smoking Gun: How the Tobacco Industry Gets Away with Murder. Wiseman, C. et al., 1998. Smoking and Body Image Concerns in Adolescent Girls. International Journal of Eating Disorders 24, 429-433. 
Table 1:

Summary Statistics of Explanatory Variables, HBSC full sample

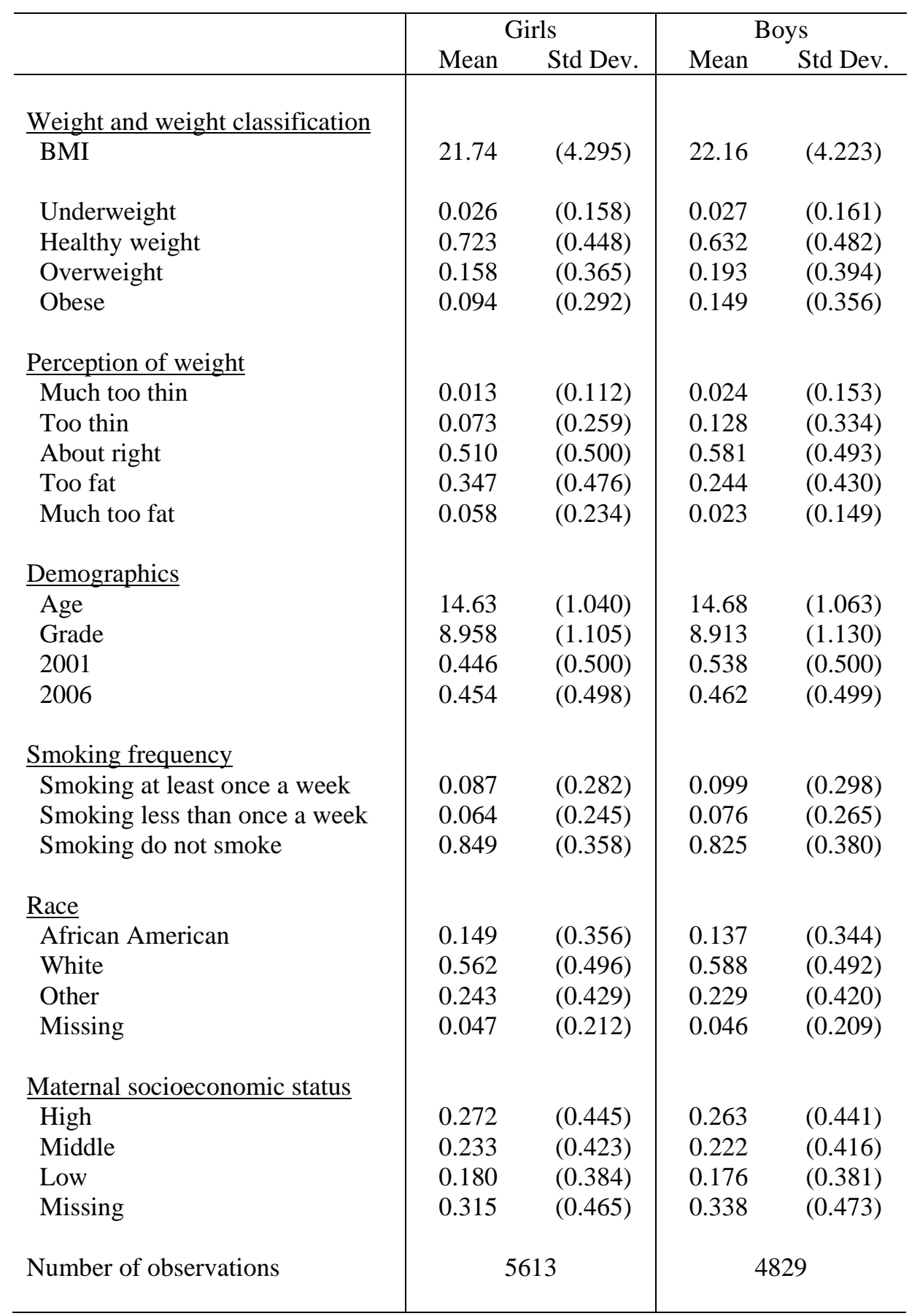


Table 2:

Summary Statistics of Explanatory Variables, NHANES full sample

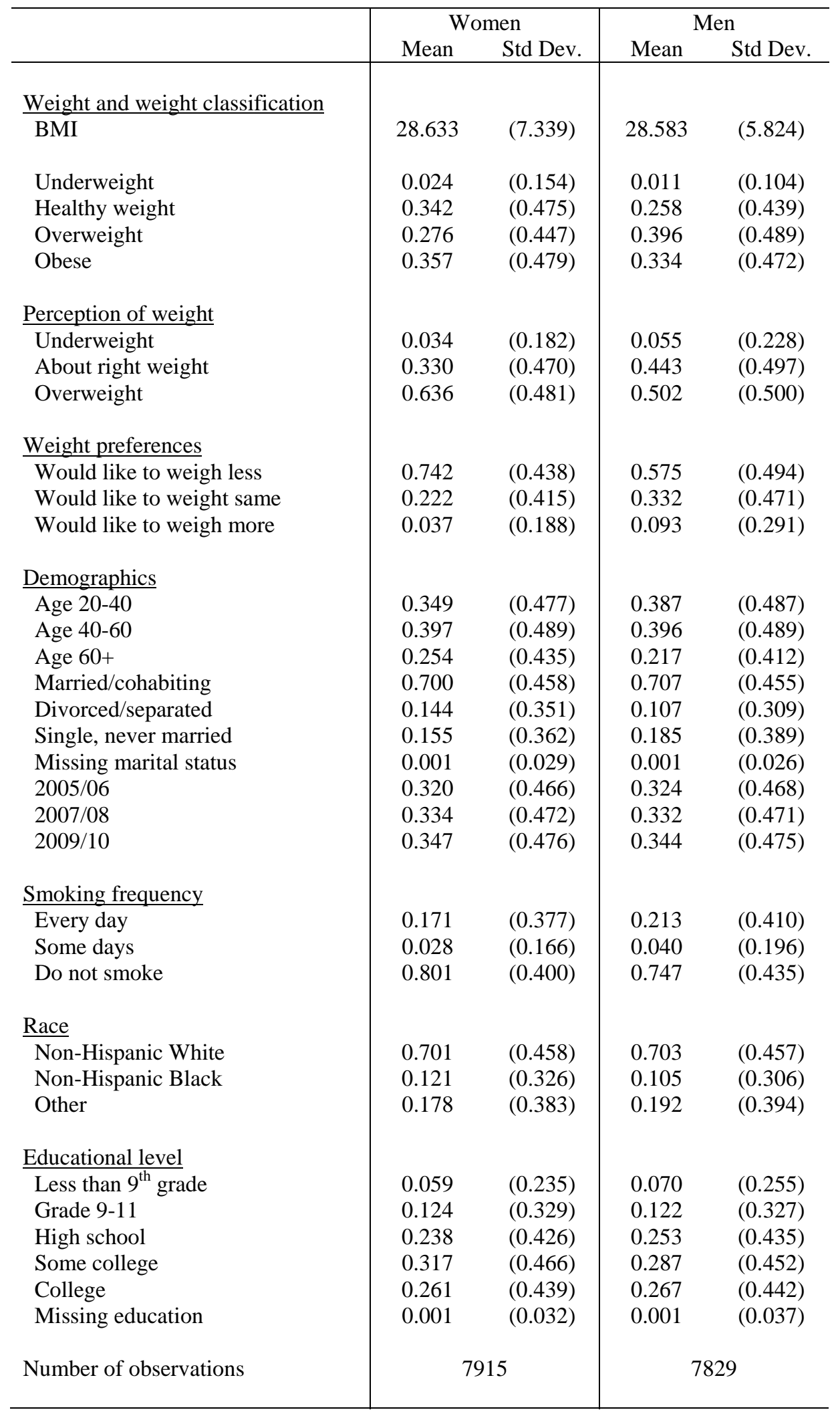


Table 3:

Proportion of smokers, and proportion indicating to use smoking to control body weight; HBSC full sample

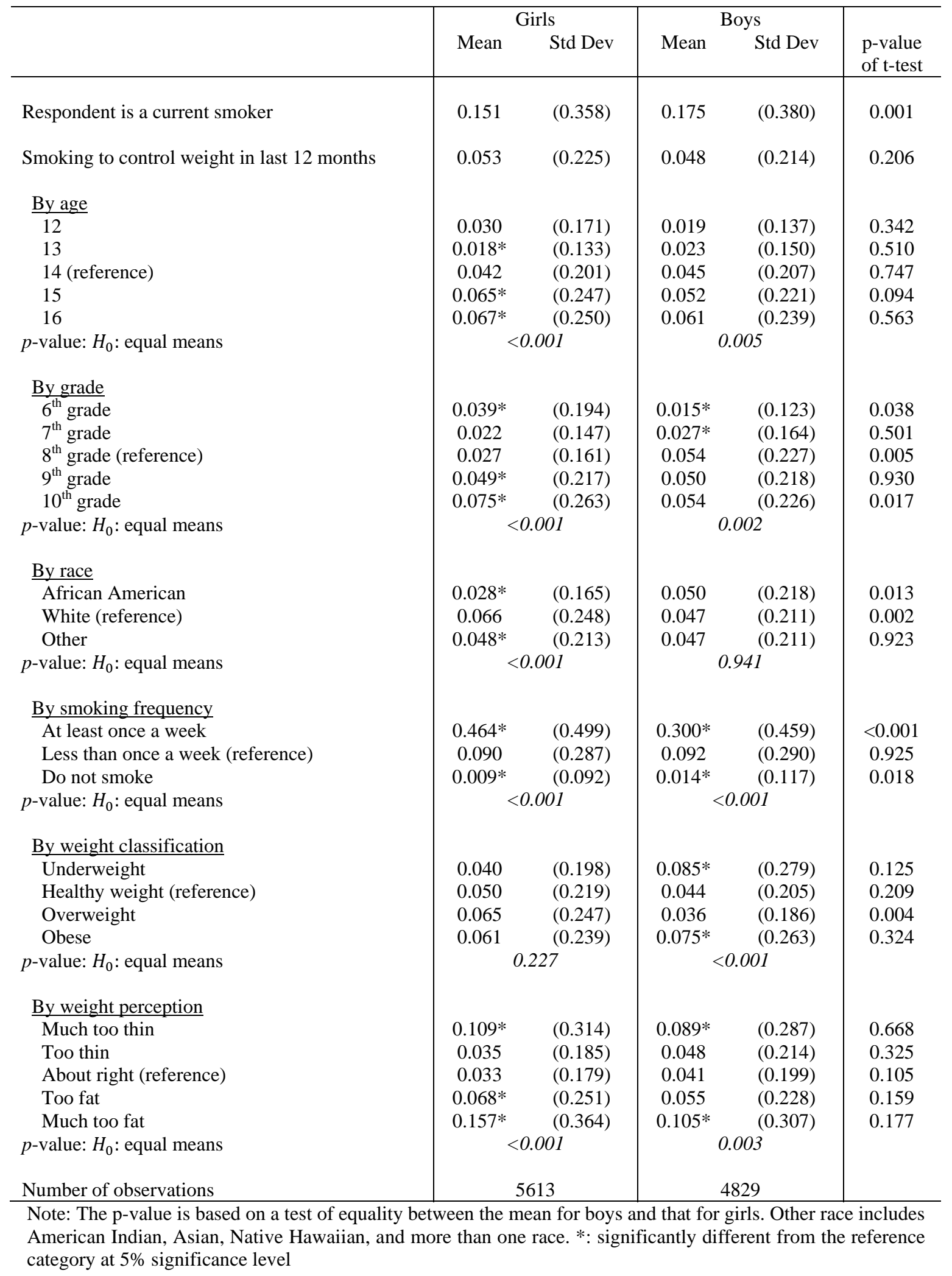


Table 4:

Proportion of smokers, and proportion indicating to use smoking to control body weight; NHANES full sample

\begin{tabular}{|c|c|c|c|c|c|}
\hline & \multicolumn{2}{|c|}{ Women } & \multicolumn{2}{|c|}{ Men } & \multirow[b]{2}{*}{ p-value of t-test } \\
\hline & Mean & Std Dev & Mean & Std Dev & \\
\hline Respondent is smoking now & 0.199 & $(0.400)$ & 0.253 & $(0.435)$ & $<0.001$ \\
\hline Smoking to control weight in past year & 0.006 & $(0.078)$ & 0.003 & $(0.057)$ & 0.008 \\
\hline $\begin{array}{l}\text { By age } \\
20-40 \\
40-60 \text { (reference) } \\
60+ \\
p \text {-value: } H_{0} \text { : equal means }\end{array}$ & $\begin{array}{c}0.008 \\
0.008 \\
0.002 *\end{array}$ & $\begin{array}{l}(0.087) \\
(0.087) \\
(0.042) \\
15\end{array}$ & $\begin{array}{l}0.004 \\
0.004 \\
0.001\end{array}$ & $\begin{array}{l}(0.066) \\
(0.060) \\
(0.023) \\
73\end{array}$ & $\begin{array}{l}0.122 \\
0.056 \\
0.191\end{array}$ \\
\hline $\begin{array}{l}\text { By race } \\
\text { Non-Hispanic white (reference) } \\
\text { Non-Hispanic Black } \\
\text { Other } \\
\text { p-value: } H_{0} \text { : equal means }\end{array}$ & $\begin{array}{c}0.005 \\
0.011^{*} \\
0.007\end{array}$ & $\begin{array}{l}(0.070) \\
(0.106) \\
(0.085) \\
52\end{array}$ & $\begin{array}{c}0.003 \\
0.008^{*} \\
0.002\end{array}$ & $\begin{array}{l}(0.053) \\
(0.086) \\
(0.050) \\
72\end{array}$ & $\begin{array}{l}0.133 \\
0.268 \\
0.015\end{array}$ \\
\hline $\begin{array}{l}\text { By smoking frequency } \\
\text { Every day } \\
\text { Some days (reference) } \\
\text { Do not smoke } \\
p \text {-value: } H_{0} \text { : equal means }\end{array}$ & $\begin{array}{c}0.027 * \\
0.044 \\
0.000^{*} \\
<\end{array}$ & $\begin{array}{l}(0.161) \\
(0.207) \\
(0.019) \\
01\end{array}$ & $\begin{array}{c}0.010^{*} \\
0.019 \\
0.000^{*}\end{array}$ & $\begin{array}{l}(0.099) \\
(0.138) \\
(0.022) \\
001\end{array}$ & $\begin{array}{l}0.001 \\
0.079 \\
0.792\end{array}$ \\
\hline $\begin{array}{l}\text { By weight classification } \\
\text { Underweight } \\
\text { Healthy weight (reference) } \\
\text { Overweight } \\
\text { Obese } \\
\text { p-value: } H_{0} \text { : equal means }\end{array}$ & $\begin{array}{l}0.000 \\
0.006 \\
0.007 \\
0.006\end{array}$ & $\begin{array}{l}(0.000) \\
(0.078) \\
(0.083) \\
(0.077) \\
93\end{array}$ & $\begin{array}{c}\mathrm{N} / \mathrm{A} \\
0.001 \\
0.002 \\
0.006^{*}\end{array}$ & $\begin{array}{l}\mathrm{N} / \mathrm{A} \\
(0.038) \\
(0.047) \\
(0.076) \\
33\end{array}$ & $\begin{array}{c}\text { N/A } \\
0.019 \\
0.009 \\
0.983\end{array}$ \\
\hline $\begin{array}{l}\text { By weight perception } \\
\text { Underweight } \\
\text { About right weight (reference) } \\
\text { Overweight } \\
p \text {-value: } H_{0} \text { : equal means }\end{array}$ & $\begin{array}{c}\text { N/A } \\
0.005 \\
0.007\end{array}$ & $\begin{array}{c}\text { N/A } \\
(0.070) \\
(0.084) \\
12\end{array}$ & $\begin{array}{c}\mathrm{N} / \mathrm{A} \\
0.001 \\
0.005^{*}\end{array}$ & $\begin{array}{c}\text { N/A } \\
(0.033) \\
(0.074) \\
02\end{array}$ & $\begin{array}{c}\text { N/A } \\
0.005 \\
0.341\end{array}$ \\
\hline $\begin{array}{l}\text { By weight preferences } \\
\text { Would like to weigh less } \\
\text { Would like to weight same (ref) } \\
\text { Would like to weigh more } \\
p \text {-value: } H_{0} \text { : equal means }\end{array}$ & $\begin{array}{c}0.0078 * \\
0.0013 \\
0.0021\end{array}$ & $\begin{array}{l}(0.088) \\
(0.036) \\
(0.046) \\
06\end{array}$ & $\begin{array}{c}0.0051^{*} \\
0.0006 \\
0.0012\end{array}$ & $\begin{array}{l}(0.071) \\
(0.025) \\
(0.034) \\
04\end{array}$ & $\begin{array}{l}0.104 \\
0.442 \\
0.702\end{array}$ \\
\hline Number of observations & & & & & \\
\hline
\end{tabular}


Table 5:

Predictors of smoking as a way to control weight, HBSC full sample

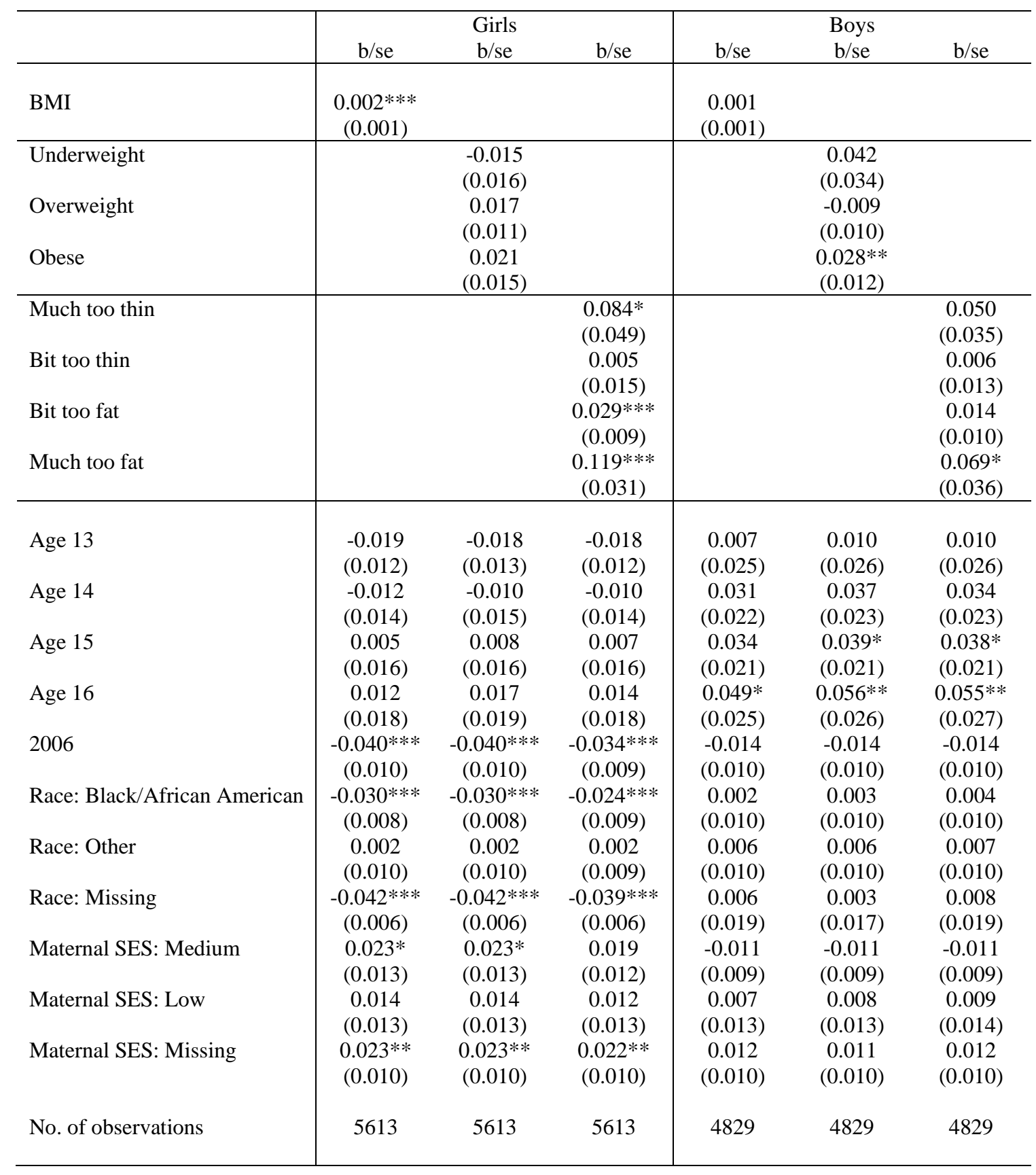

Notes: The dependent variable equals 1 when the individual indicates to smoke for weight control. The reference category is a white 14-year old with a healthy weight in 2001, who perceives its weight to be about right, and average maternal SES; * $\mathrm{p}<0.10, * * \mathrm{p}<0.05, * * * \mathrm{p}<0.01$ 
Table 6

Cross-tabulation of weight categories by self-perception of weight, HBSC full sample

\begin{tabular}{lcccccc}
\hline & $\begin{array}{c}\text { Much } \\
\text { too thin }\end{array}$ & Too thin & $\begin{array}{c}\text { About } \\
\text { right }\end{array}$ & $\begin{array}{c}\text { Bit too } \\
\text { fat }\end{array}$ & $\begin{array}{c}\text { Much too } \\
\text { fat }\end{array}$ & Total \\
\hline Girls & & & & & & \\
\hline Underweight & 13.26 & 23.29 & 55.02 & 7.84 & 0.58 & 100 \\
Healthy weight & 1.25 & 9.13 & 60.22 & 27.15 & 2.25 & 100 \\
Overweight & 0.12 & 0.25 & 30.26 & 60.09 & 9.29 & 100 \\
Obese & - & 0.21 & 13.39 & 57.39 & 29.01 & 100 \\
& & & & & & \\
Boys & 17.00 & 33.22 & 45.89 & 3.18 & 0.71 & 100 \\
$\quad$ Underweight & 2.83 & 18.19 & 68.27 & 10.19 & 0.52 & 100 \\
Healthy weight & 0.37 & 1.98 & 53.14 & 42.52 & 2.00 & 100 \\
Overweight & 0.57 & 0.19 & 23.59 & 65.28 & 10.37 & 100 \\
Obese & & & & & & \\
\hline
\end{tabular}

Notes: clinical weight classification is based on self-reported weight and height. 
Table 7:

Predictors of smoking as a way to control weight, conditional on reporting to be a current smoker, HBSC

\begin{tabular}{|c|c|c|c|c|c|c|}
\hline & \multicolumn{3}{|c|}{ Girls } & \multicolumn{3}{|c|}{ Boys } \\
\hline & $\mathrm{b} / \mathrm{se}$ & $\mathrm{b} / \mathrm{se}$ & $\mathrm{b} / \mathrm{se}$ & $\mathrm{b} / \mathrm{se}$ & $\mathrm{b} / \mathrm{se}$ & $\mathrm{b} / \mathrm{se}$ \\
\hline BMI & $\begin{array}{c}0.002 \\
(0.004)\end{array}$ & & & $\begin{array}{c}0.002 \\
(0.004)\end{array}$ & & \\
\hline Underweight & & $\begin{array}{c}0.223 \\
(0.178)\end{array}$ & & & $\begin{array}{c}0.321 * * \\
(0.138)\end{array}$ & \\
\hline Overweight & & $\begin{array}{c}0.062 \\
(0.061)\end{array}$ & & & $\begin{array}{c}-0.092 * * \\
(0.043)\end{array}$ & \\
\hline Obese & & $\begin{array}{c}0.066 \\
(0.078)\end{array}$ & & & $\begin{array}{l}0.090 * \\
(0.053)\end{array}$ & \\
\hline Much too thin & & & $\begin{array}{c}0.221 \\
(0.176)\end{array}$ & & & $\begin{array}{c}0.082 \\
(0.123)\end{array}$ \\
\hline Bit too thin & & & $\begin{array}{c}0.059 \\
(0.103)\end{array}$ & & & $\begin{array}{c}-0.008 \\
(0.055)\end{array}$ \\
\hline Bit too fat & & & $\begin{array}{c}0.141^{* * *} \\
(0.049)\end{array}$ & & & $\begin{array}{c}0.029 \\
(0.046)\end{array}$ \\
\hline Much too fat & & & $\begin{array}{c}0.268 * * * \\
(0.078)\end{array}$ & & & $\begin{array}{c}-0.010 \\
(0.092) \\
\end{array}$ \\
\hline Age 13 & $\begin{array}{c}0.041 \\
(0.206)\end{array}$ & $\begin{array}{c}0.056 \\
(0.208)\end{array}$ & $\begin{array}{c}0.091 \\
(0.219)\end{array}$ & $\begin{array}{c}0.088 \\
(0.174)\end{array}$ & $\begin{array}{c}0.088 \\
(0.178)\end{array}$ & $\begin{array}{c}0.087 \\
(0.175)\end{array}$ \\
\hline Age 14 & $\begin{array}{c}0.070 \\
(0.186)\end{array}$ & $\begin{array}{c}0.090 \\
(0.184)\end{array}$ & $\begin{array}{c}0.121 \\
(0.189)\end{array}$ & $\begin{array}{c}0.000 \\
(0.131)\end{array}$ & $\begin{array}{c}0.021 \\
(0.135)\end{array}$ & $\begin{array}{l}-0.002 \\
(0.131)\end{array}$ \\
\hline Age 15 & $\begin{array}{c}0.149 \\
(0.176)\end{array}$ & $\begin{array}{c}0.167 \\
(0.171)\end{array}$ & $\begin{array}{c}0.205 \\
(0.174)\end{array}$ & $\begin{array}{l}-0.033 \\
(0.129)\end{array}$ & $\begin{array}{l}-0.028 \\
(0.129)\end{array}$ & $\begin{array}{c}-0.036 \\
(0.130)\end{array}$ \\
\hline Age 16 & $\begin{array}{c}0.114 \\
(0.186)\end{array}$ & $\begin{array}{c}0.130 \\
(0.182)\end{array}$ & $\begin{array}{c}0.167 \\
(0.187)\end{array}$ & $\begin{array}{l}-0.013 \\
(0.129)\end{array}$ & $\begin{array}{l}-0.014 \\
(0.128)\end{array}$ & $\begin{array}{l}-0.010 \\
(0.130)\end{array}$ \\
\hline 2006 & $\begin{array}{c}-0.132^{* * *} \\
(0.048)\end{array}$ & $\begin{array}{c}-0.137 * * * \\
(0.047)\end{array}$ & $\begin{array}{c}-0.127 * * * \\
(0.046)\end{array}$ & $\begin{array}{c}0.000 \\
(0.039)\end{array}$ & $\begin{array}{c}-0.009 \\
(0.037)\end{array}$ & $\begin{array}{l}-0.001 \\
(0.038)\end{array}$ \\
\hline Race: Black/African American & $\begin{array}{c}-0.152^{* * * *} \\
(0.054)\end{array}$ & $\begin{array}{c}-0.161^{* * * *} \\
(0.054)\end{array}$ & $\begin{array}{c}-0.128 * * \\
(0.056)\end{array}$ & $\begin{array}{l}-0.006 \\
(0.047)\end{array}$ & $\begin{array}{c}0.004 \\
(0.045)\end{array}$ & $\begin{array}{l}-0.000 \\
(0.047)\end{array}$ \\
\hline Race: Other & $\begin{array}{c}0.014 \\
(0.060)\end{array}$ & $\begin{array}{c}0.011 \\
(0.059)\end{array}$ & $\begin{array}{c}0.020 \\
(0.060)\end{array}$ & $\begin{array}{c}0.028 \\
(0.059)\end{array}$ & $\begin{array}{c}0.031 \\
(0.057)\end{array}$ & $\begin{array}{c}0.030 \\
(0.058)\end{array}$ \\
\hline Race: Missing & $\begin{array}{c}-0.291^{* * * *} \\
(0.030)\end{array}$ & $\begin{array}{c}-0.291 * * * \\
(0.030)\end{array}$ & $\begin{array}{c}-0.280 * * * \\
(0.033)\end{array}$ & $\begin{array}{c}0.069 \\
(0.088)\end{array}$ & $\begin{array}{c}0.027 \\
(0.070)\end{array}$ & $\begin{array}{c}0.073 \\
(0.087)\end{array}$ \\
\hline Maternal SES: Medium & $\begin{array}{l}-0.034 \\
(0.060)\end{array}$ & $\begin{array}{l}-0.037 \\
(0.059)\end{array}$ & $\begin{array}{l}-0.051 \\
(0.061)\end{array}$ & $\begin{array}{l}-0.027 \\
(0.051)\end{array}$ & $\begin{array}{l}-0.022 \\
(0.051)\end{array}$ & $\begin{array}{l}-0.030 \\
(0.051)\end{array}$ \\
\hline Maternal SES: Low & $\begin{array}{l}-0.016 \\
(0.068)\end{array}$ & $\begin{array}{l}-0.021 \\
(0.067)\end{array}$ & $\begin{array}{l}-0.010 \\
(0.070)\end{array}$ & $\begin{array}{c}0.014 \\
(0.057)\end{array}$ & $\begin{array}{c}0.030 \\
(0.060)\end{array}$ & $\begin{array}{c}0.019 \\
(0.058)\end{array}$ \\
\hline Maternal SES: Missing & $\begin{array}{c}0.055 \\
(0.062)\end{array}$ & $\begin{array}{c}0.054 \\
(0.061)\end{array}$ & $\begin{array}{c}0.044 \\
(0.062)\end{array}$ & $\begin{array}{c}0.068 \\
(0.055)\end{array}$ & $\begin{array}{c}0.065 \\
(0.053)\end{array}$ & $\begin{array}{c}0.070 \\
(0.054)\end{array}$ \\
\hline No. of observations & 761 & 761 & 761 & 724 & 724 & 724 \\
\hline
\end{tabular}

Notes: The dependent variable equals 1 when the individual indicates to smoke for weight control. The sample only includes those who indicate they are current smokers (i.e. at least once a week or less than once a week). The reference category is a white 14-year old with a healthy weight in 2001, who perceives its weight to be about right, and average maternal SES; * $\mathrm{p}<0.10, * * \mathrm{p}<0.05, * * * \mathrm{p}<0.01$ 
Table 8:

Predictors of smoking as a way to control weight, conditional on attempting to control your weight, HBSC

\begin{tabular}{|c|c|c|c|c|c|c|}
\hline & \multicolumn{3}{|c|}{ Girls } & \multicolumn{3}{|c|}{ Boys } \\
\hline & $\mathrm{b} / \mathrm{se}$ & $\mathrm{b} / \mathrm{se}$ & $\mathrm{b} / \mathrm{se}$ & $\mathrm{b} / \mathrm{se}$ & $\mathrm{b} / \mathrm{se}$ & $\mathrm{b} / \mathrm{se}$ \\
\hline BMI & $\begin{array}{l}0.001^{*} \\
(0.001)\end{array}$ & & & $\begin{array}{c}0.001 \\
(0.001)\end{array}$ & & \\
\hline Underweight & & $\begin{array}{c}-0.010 \\
(0.020)\end{array}$ & & & $\begin{array}{c}0.044 \\
(0.038)\end{array}$ & \\
\hline Overweight & & $\begin{array}{c}0.016 \\
(0.011)\end{array}$ & & & $\begin{array}{l}-0.016 \\
(0.010)\end{array}$ & \\
\hline Obese & & $\begin{array}{c}0.017 \\
(0.015)\end{array}$ & & & $\begin{array}{c}0.024 * * \\
(0.012)\end{array}$ & \\
\hline Much too thin & & & $\begin{array}{c}0.165 * * \\
(0.073)\end{array}$ & & & $\begin{array}{c}0.076 \\
(0.047)\end{array}$ \\
\hline Bit too thin & & & $\begin{array}{c}0.010 \\
(0.017)\end{array}$ & & & $\begin{array}{c}0.008 \\
(0.015)\end{array}$ \\
\hline Bit too fat & & & $\begin{array}{c}0.029 * * * \\
(0.009)\end{array}$ & & & $\begin{array}{c}0.010 \\
(0.010)\end{array}$ \\
\hline Much too fat & & & $\begin{array}{c}0.117^{* * *} \\
(0.031)\end{array}$ & & & $\begin{array}{l}0.070 * \\
(0.038)\end{array}$ \\
\hline Age 13 & -0.020 & -0.019 & -0.019 & 0.009 & 0.013 & 0.013 \\
\hline Age 14 & $\begin{array}{l}-0.011 \\
(0.015)\end{array}$ & $\begin{array}{c}-0.010 \\
(0.015)\end{array}$ & $\begin{array}{c}-0.010 \\
(0.015)\end{array}$ & $\begin{array}{c}0.033 \\
(0.024)\end{array}$ & $\begin{array}{c}0.039 \\
(0.025)\end{array}$ & $\begin{array}{c}0.037 \\
(0.026)\end{array}$ \\
\hline Age 15 & $\begin{array}{c}0.007 \\
(0.017)\end{array}$ & $\begin{array}{c}0.009 \\
(0.017)\end{array}$ & $\begin{array}{c}0.008 \\
(0.016)\end{array}$ & $\begin{array}{l}0.038^{*} \\
(0.023)\end{array}$ & $\begin{array}{l}0.043^{*} \\
(0.023)\end{array}$ & $\begin{array}{l}0.042 * \\
(0.024)\end{array}$ \\
\hline Age 16 & $\begin{array}{c}0.014 \\
(0.019)\end{array}$ & $\begin{array}{c}0.019 \\
(0.020)\end{array}$ & $\begin{array}{c}0.015 \\
(0.019)\end{array}$ & $\begin{array}{c}0.056 * * \\
(0.028)\end{array}$ & $\begin{array}{c}0.060 * * \\
(0.029)\end{array}$ & $\begin{array}{c}0.060 * * \\
(0.029)\end{array}$ \\
\hline 2006 & $\begin{array}{c}-0.042^{* * *} \\
(0.010)\end{array}$ & $\begin{array}{c}-0.042 * * * \\
(0.010)\end{array}$ & $\begin{array}{c}-0.036 * * * \\
(0.010)\end{array}$ & $\begin{array}{c}-0.018^{*} \\
(0.011)\end{array}$ & $\begin{array}{c}-0.019 * \\
(0.011)\end{array}$ & $\begin{array}{c}-0.018^{*} \\
(0.011)\end{array}$ \\
\hline Race: Black/African American & $\begin{array}{c}-0.030 * * * \\
(0.009)\end{array}$ & $\begin{array}{c}-0.030 * * * \\
(0.009)\end{array}$ & $\begin{array}{c}-0.024 * * * \\
(0.009)\end{array}$ & $\begin{array}{c}0.002 \\
(0.012)\end{array}$ & $\begin{array}{c}0.003 \\
(0.012)\end{array}$ & $\begin{array}{c}0.003 \\
(0.012)\end{array}$ \\
\hline Race: Other & $\begin{array}{c}0.003 \\
(0.010)\end{array}$ & $\begin{array}{c}0.003 \\
(0.010)\end{array}$ & $\begin{array}{c}0.002 \\
(0.010)\end{array}$ & $\begin{array}{c}0.007 \\
(0.011)\end{array}$ & $\begin{array}{c}0.007 \\
(0.011)\end{array}$ & $\begin{array}{c}0.007 \\
(0.011)\end{array}$ \\
\hline Race: Missing & $\begin{array}{c}-0.045^{* * *} \\
(0.006)\end{array}$ & $\begin{array}{c}-0.044^{* * *} \\
(0.006)\end{array}$ & $\begin{array}{c}-0.041^{* * *} \\
(0.006)\end{array}$ & $\begin{array}{c}0.002 \\
(0.020)\end{array}$ & $\begin{array}{c}0.001 \\
(0.018)\end{array}$ & $\begin{array}{c}0.005 \\
(0.020)\end{array}$ \\
\hline Maternal SES: Medium & $\begin{array}{l}0.026^{*} \\
(0.014)\end{array}$ & $\begin{array}{l}0.026^{*} \\
(0.014)\end{array}$ & $\begin{array}{l}0.021^{*} \\
(0.013)\end{array}$ & $\begin{array}{c}-0.014 \\
(0.010)\end{array}$ & $\begin{array}{c}-0.014 \\
(0.010)\end{array}$ & $\begin{array}{c}-0.014 \\
(0.010)\end{array}$ \\
\hline Maternal SES: Low & $\begin{array}{c}0.016 \\
(0.015)\end{array}$ & $\begin{array}{c}0.016 \\
(0.014)\end{array}$ & $\begin{array}{c}0.015 \\
(0.014)\end{array}$ & $\begin{array}{c}0.007 \\
(0.015)\end{array}$ & $\begin{array}{c}0.007 \\
(0.015)\end{array}$ & $\begin{array}{c}0.009 \\
(0.015)\end{array}$ \\
\hline Maternal SES: Missing & $\begin{array}{c}0.026 * * \\
(0.011)\end{array}$ & $\begin{array}{c}0.026 * * \\
(0.011)\end{array}$ & $\begin{array}{c}0.025 * * \\
(0.011)\end{array}$ & $\begin{array}{c}0.014 \\
(0.011)\end{array}$ & $\begin{array}{c}0.013 \\
(0.011)\end{array}$ & $\begin{array}{c}0.014 \\
(0.011)\end{array}$ \\
\hline No. of observations & 5283 & 5283 & 5283 & 4351 & 4351 & 4351 \\
\hline
\end{tabular}

Notes: The dependent variable equals 1 when the individual indicates to smoke for weight control. The sample only includes those who indicate they have attempted to control their weight in the last 12 months. The reference category is a white 14year old with a healthy weight in 2001, who perceives its weight to be about right, and average maternal SES; * $\mathrm{p}<0.10$, ** $\mathrm{p}<0.05,{ }^{* * *} \mathrm{p}<0.01$ 


\section{Appendix A: Proportion of boys and girls using specific weight control strategies}

Table A.1: Weight control strategies used in the HBSC: sample of girls and boys who responded to the question on weight control, and the sample conditional on smoking for weight control

\begin{tabular}{|c|c|c|c|c|c|c|c|}
\hline & \multicolumn{2}{|c|}{ Girls } & \multirow[b]{2}{*}{$\begin{array}{c}\text { No. of } \\
\text { obs. }\end{array}$} & \multicolumn{3}{|c|}{ Boys } & \multirow[b]{2}{*}{$\begin{array}{l}\mathrm{p} \text {-value } \\
\text { of t-test }\end{array}$} \\
\hline & Mean & $\begin{array}{c}\text { Std } \\
\text { Dev }\end{array}$ & & Mean & $\begin{array}{c}\text { Std } \\
\text { Dev }\end{array}$ & $\begin{array}{c}\text { No. of } \\
\text { obs. }\end{array}$ & \\
\hline $\begin{array}{l}\text { Weight control behaviors, full sample: } \\
\text { Exercise } \\
\text { Eat more fruit and/or vegetables } \\
\text { Eat fewer sweets } \\
\text { Eat less fat } \\
\text { Drink fewer soft drinks } \\
\text { Eat less (smaller amounts) } \\
\text { Fasting } \\
\text { Use diet pills or laxatives } \\
\text { Vomiting } \\
\text { Smoke more } \\
\text { Diet under supervision of professional } \\
\text { Other }\end{array}$ & $\begin{array}{l}0.848 \\
0.631 \\
0.628 \\
0.589 \\
0.553 \\
0.538 \\
0.177 \\
0.067 \\
0.057 \\
0.053 \\
0.051 \\
0.028\end{array}$ & $\begin{array}{l}(0.359) \\
(0.482) \\
(0.483) \\
(0.492) \\
(0.497) \\
(0.499) \\
(0.382) \\
(0.250) \\
(0.233) \\
(0.225) \\
(0.220) \\
(0.164)\end{array}$ & $\begin{array}{l}5598 \\
5567 \\
5595 \\
5586 \\
5576 \\
5581 \\
2280 \\
5600 \\
5594 \\
5613 \\
5533 \\
2321\end{array}$ & $\begin{array}{c}0.842 \\
0.522 \\
0.487 \\
0.429 \\
0.41 \\
0.302 \\
0.073 \\
0.033 \\
0.027 \\
0.048 \\
0.036 \\
0.026\end{array}$ & $\begin{array}{l}(0.365) \\
(0.500) \\
(0.500) \\
(0.495) \\
(0.492) \\
(0.459) \\
(0.261) \\
(0.179) \\
(0.162) \\
(0.214) \\
(0.185) \\
(0.159)\end{array}$ & $\begin{array}{l}4822 \\
4806 \\
4819 \\
4809 \\
4817 \\
4810 \\
1865 \\
4816 \\
4814 \\
4829 \\
4778 \\
1923\end{array}$ & $\begin{array}{c}0.412 \\
<0.001 \\
<0.001 \\
<0.001 \\
<0.001 \\
<0.001 \\
<0.001 \\
<0.001 \\
<0.001 \\
0.206 \\
<0.001 \\
0.718\end{array}$ \\
\hline $\begin{array}{l}\text { Weight control behaviors, conditional } \\
\text { on smoking for weight control } \\
\text { Exercise } \\
\text { Eat less (smaller amounts) } \\
\text { Eat fewer sweets } \\
\text { Eat less fat } \\
\text { Drink fewer soft drinks } \\
\text { Eat more fruit and/or vegetables } \\
\text { Fasting } \\
\text { Use diet pills or laxatives } \\
\text { Vomiting } \\
\text { Diet under supervision of professional } \\
\text { Other }\end{array}$ & $\begin{array}{l}0.823 \\
0.752 \\
0.705 \\
0.654 \\
0.582 \\
0.566 \\
0.420 \\
0.387 \\
0.276 \\
0.097 \\
0.019\end{array}$ & $\begin{array}{l}(0.382) \\
(0.433) \\
(0.457) \\
(0.477) \\
(0.494) \\
(0.497) \\
(0.495) \\
(0.488) \\
(0.448) \\
(0.296) \\
(0.139)\end{array}$ & $\begin{array}{l}262 \\
261 \\
259 \\
260 \\
259 \\
256 \\
144 \\
257 \\
260 \\
253 \\
147\end{array}$ & $\begin{array}{l}0.832 \\
0.481 \\
0.574 \\
0.467 \\
0.415 \\
0.570 \\
0.275 \\
0.338 \\
0.271 \\
0.160 \\
0.018\end{array}$ & $\begin{array}{l}(0.375) \\
(0.501) \\
(0.496) \\
(0.500) \\
(0.494) \\
(0.496) \\
(0.449) \\
(0.474) \\
(0.446) \\
(0.368) \\
(0.134)\end{array}$ & $\begin{array}{l}221 \\
218 \\
219 \\
218 \\
219 \\
219 \\
102 \\
218 \\
219 \\
215 \\
104\end{array}$ & $\begin{array}{c}0.801 \\
<0.001 \\
0.003 \\
<0.001 \\
<0.001 \\
0.929 \\
0.020 \\
0.268 \\
0.915 \\
0.038 \\
0.942\end{array}$ \\
\hline
\end{tabular}

Note: The p-value is based on a test of equality between the mean for boys and that for girls. The upper panel shows the proportion of girls and boys in the full sample that engages in the different weight control behaviors. The lower panel shows the averages conditional on the respondent indicating to smoke for weight control. 
Table A.2: Weight control strategies in the NHANES: full sample of women and men, and conditional on smoking for weight control

\begin{tabular}{|c|c|c|c|c|c|}
\hline & \multicolumn{2}{|c|}{ Women } & \multicolumn{2}{|c|}{ Men } & \multirow[b]{2}{*}{$\mathrm{p}$-value } \\
\hline & Mean & Std Dev & Mean & Std Dev & \\
\hline \multicolumn{6}{|l|}{ Weight control behaviors, full sample: } \\
\hline Eat less food & 0.384 & $(0.486)$ & 0.272 & $(0.445)$ & $<0.001$ \\
\hline Exercised & 0.373 & $(0.484)$ & 0.294 & $(0.456)$ & $<0.001$ \\
\hline Drink a lot of water & 0.262 & $(0.440)$ & 0.153 & $(0.360)$ & $<0.001$ \\
\hline Eat less fat & 0.246 & $(0.431)$ & 0.173 & $(0.378)$ & $<0.001$ \\
\hline Switch to food with lower calories & 0.226 & $(0.418)$ & 0.141 & $(0.348)$ & $<0.001$ \\
\hline Eat fewer carbohydrates & 0.165 & $(0.371)$ & 0.112 & $(0.315)$ & $<0.001$ \\
\hline Skip meals & 0.097 & $(0.295)$ & 0.073 & $(0.260)$ & $<0.001$ \\
\hline Eat diet foods & 0.081 & $(0.273)$ & 0.043 & $(0.202)$ & $<0.001$ \\
\hline Eat more fruit, vegetables and salad & 0.083 & $(0.276)$ & 0.056 & $(0.230)$ & $<0.001$ \\
\hline Eat less sugar, candy, sweets & 0.058 & $(0.234)$ & 0.046 & $(0.211)$ & $<0.001$ \\
\hline Join a weight loss program & 0.059 & $(0.236)$ & 0.007 & $(0.081)$ & $<0.001$ \\
\hline Change eating habits & 0.057 & $(0.232)$ & 0.041 & $(0.197)$ & $<0.001$ \\
\hline Take non-Rx supplements & 0.044 & $(0.205)$ & 0.021 & $(0.142)$ & $<0.001$ \\
\hline ial diet & 0.045 & $(0.207)$ & 0.027 & $(0.161)$ & $<0.001$ \\
\hline Liquid c & 0.034 & $(0.182)$ & 0.015 & $(0.122)$ & $<0.001$ \\
\hline Take prescription diet pills & 0.018 & $(0.132)$ & 0.004 & $(0.061)$ & $<0.001$ \\
\hline Other & 0.010 & $(0.101)$ & 0.008 & $(0.090)$ & 0.167 \\
\hline Start to sI & 0.006 & $(0.078)$ & 0.003 & $(0.057)$ & 0.008 \\
\hline Tak & 0.005 & $(0.072)$ & 0.002 & $(0.045)$ & $<0.001$ \\
\hline Number of observations & \multicolumn{2}{|c|}{7915} & \multicolumn{2}{|c|}{7829} & \\
\hline \multirow{2}{*}{\multicolumn{6}{|c|}{$\begin{array}{l}\text { Weight control behaviors, conditional } \\
\text { on smoking for weight control }\end{array}$}} \\
\hline & & & & & \\
\hline Eat less food & 0.629 & $(0.488)$ & 0.940 & $(0.242)$ & 0.004 \\
\hline Drink a lot of water & 0.588 & $(0.498)$ & 0.642 & $(0.489)$ & 0.663 \\
\hline Eat less fat & 0.597 & $(0.496)$ & 0.411 & $(0.502)$ & 0.139 \\
\hline Exercised & 0.566 & $(0.501)$ & 0.426 & $(0.505)$ & 0.270 \\
\hline Skip meals & 0.530 & $(0.504)$ & 0.531 & $(0.509)$ & 0.993 \\
\hline Switch to food & 0.486 & $(0.505)$ & 0.379 & $(0.495)$ & 0.397 \\
\hline Eat fewer carbohydrates & 0.270 & $(0.449)$ & 0.448 & $(0.508)$ & 0.134 \\
\hline Eat more fruit, vegetables and salad & 0.270 & $(0.449)$ & 0.067 & $(0.255)$ & 0.044 \\
\hline Eat diet foods & 0.209 & $(0.411)$ & 0.182 & $(0.394)$ & 0.791 \\
\hline Change eating & 0.189 & $(0.396)$ & 0.034 & $(0.184)$ & 0.072 \\
\hline Follow a special diet & 0.170 & $(0.380)$ & 0.215 & $(0.419)$ & 0.649 \\
\hline Take non-Rx supplem & 0.130 & $(0.340)$ & 0.228 & $(0.428)$ & 0.293 \\
\hline Join a weight loss program & 0.122 & $(0.331)$ & 0.089 & $(0.291)$ & 0.678 \\
\hline Liquid diet formula & 0.091 & $(0.291)$ & 0.175 & $(0.387)$ & 0.312 \\
\hline Eat less sugar, candy, & 0.073 & $(0.263)$ & 0.052 & $(0.228)$ & 0.748 \\
\hline Take prescription diet pills & 0.060 & $(0.241)$ & 0.069 & $(0.258)$ & 0.893 \\
\hline Take laxatives or vomit & 0.054 & $(0.229)$ & N/A & N/A & 0.250 \\
\hline Othe & 0.008 & $(0.091)$ & N/A & N/A & 0.662 \\
\hline Number of observations & & & & & \\
\hline
\end{tabular}

Note: The p-value is based on a test of equality between the mean for men and that for women; N/A implies none of the respondents engaged in this weight control behavior. The upper panel shows the proportion of women and men in the full sample that engages in the different weight control behaviors. The lower panel shows the averages conditional on the respondent indicating to smoke for weight control. 